\title{
Platysma muscle additionally innervated by a variant anterior branch of the great auricular nerve
}

\author{
T. Jovanovski', N. Umek' ${ }^{1}$, A. Kansky², E. Cvetko ${ }^{1}$ \\ ${ }^{1}$ Institute of Anatomy, Faculty of Medicine, University of Ljubljana, Slovenia \\ ${ }^{2}$ Department of Maxillofacial and Oral Surgery, University Medical Centre, Ljubljana, Slovenia
}

[Received: 25 November 2019; Accepted: 16 January 2020]

\begin{abstract}
Damage to the great auricular nerve, with consequent clinical deficits, is a common surgical complication in facial aesthetic and in head and neck procedures such as parotidectomy, neck dissection, rhytidectomy and platysma flap operations. Hence, a thorough knowledge of nerve anatomy, particularly its potential variations, is critical in reducing the associated operative morbidity. Accordingly, we report an unusual variation of the anterior branch of the great auricular nerve noted in an 81-year-old female cadaver. The nerve was observed to course into the submandibular region anterior and superficial to the internal jugular vein, communicating with the cervical branch of the facial nerve, while independently innervating the platysma muscle. Although several anatomical variations of the branches of the cervical plexus have been documented, our report describes unique innervation of the platysma muscle by the great auricular nerve, which provides a new insight on the motor component of the nerve. (Folia Morphol 2020; 79, 4: 863-866)
\end{abstract}

Key words: anatomic variation, great auricular nerve, rhytidectomy, parotidectomy, platysma muscle

\section{INTRODUCTION}

The great auricular nerve arises from the ventral rami of the second and the third cervical spinal nerves, to fuse into its main trunk before emerging from the posterior border of the sternocleidomastoid muscle at the junction of its upper and middle third, where it resides in its most superficial location - the great auricular point [1, 3]. It courses superiorly and anteriorly, and divides into the anterior and posterior branches. The anterior branch continues in a plane between the sternocleidomastoid muscle and the parotid gland prior to its terminal arborisation, providing sensation to the skin overlying the parotid gland and anteroinferior aspect of the auricle [8]. The posterior branch courses on the surface of the sternocleidomastoid muscle before reaching the mastoid area and terminating in the postauricular area to give sensation to the posterioinferior aspect of the auricle [8]. Clinically, injury to the great auricular nerve is a common complication in surgical procedures in face, head and neck, notably rhytidectomy, parotidectomy and platysma flap surgery, occurring at a rate of $6 \%$ to $7 \%$ during rhytidectomy $[2,7,8]$. latrogenic or inevitable amputation of the nerve during such procedures could incur significant complications such as dysesthesia or allodynia in the involved skin area, otalgia, discomfort on cold exposure, and traumatic neuroma [11]. To minimise the risk of injury to the great auricular nerve during head and neck surgical procedures, it is important to fully appreciate the potential variations in its anatomical disposition. In the present report, we describe an anatomic variation of 

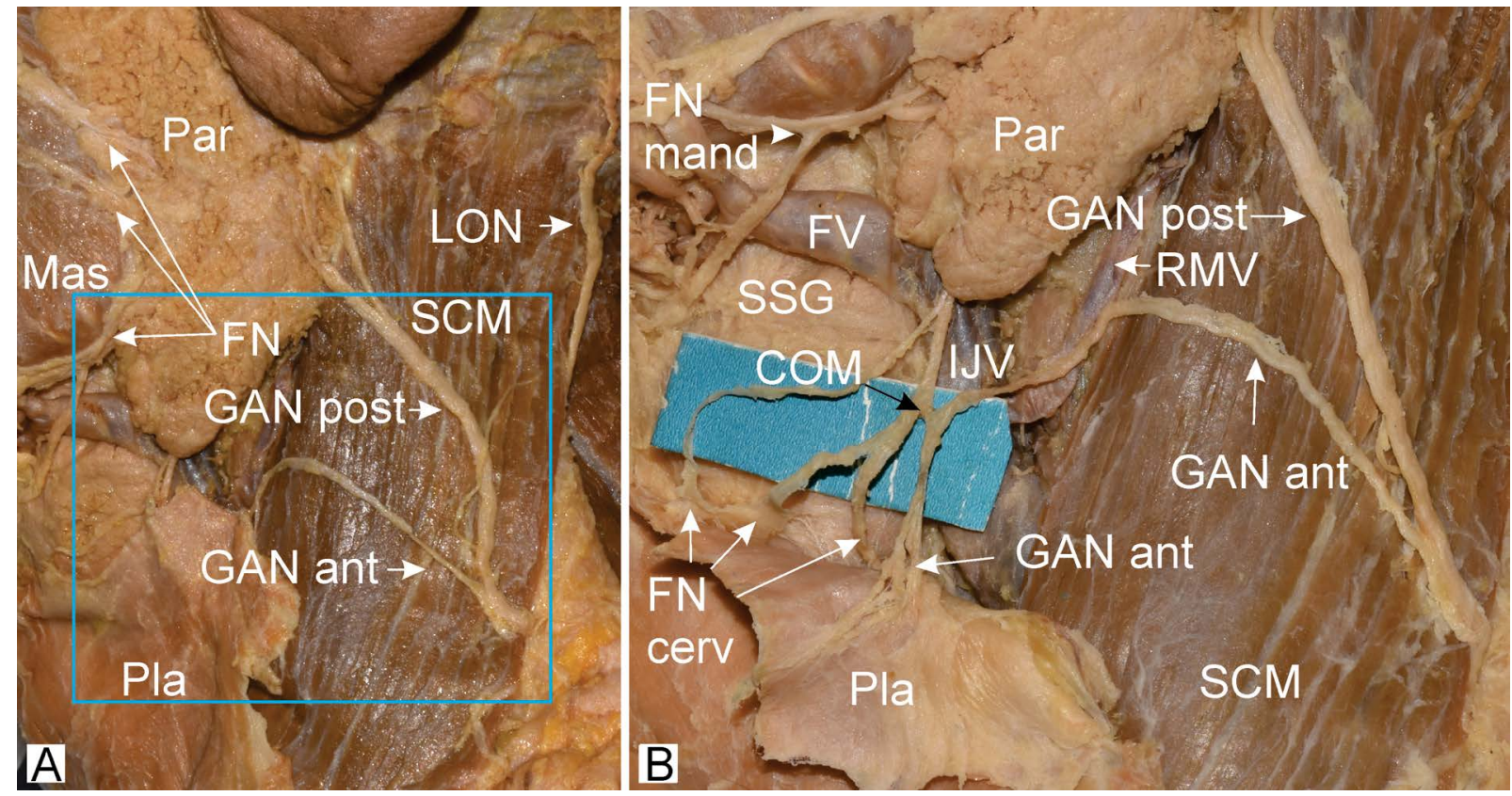

Figure 1. Dissection of the left side of the neck showing the anterior branch of the great auricular nerve innervating the platysma muscle; A. Superficial dissection; B. Magnified view with the platysma muscle reflected; GAN ant — great auricular nerve, anterior branch; GAN post — great auricular nerve, posterior branch; COM — communicating branch; Par — parotid gland; SCM — sternocleidomastoid muscle; LON — lesser occipital nerve; FN — facial nerve; FN mand - mandibular branch of facial nerve; FN cerv — cervical branch of facial nerve; $\mathrm{Pla}$ — platysma muscle; FV — facial vein; RMV — retromandibular vein; IJV — internal jugular vein; SSG — submandibular salivary gland.

the nerve observed during a cadaver dissection — an anterior branch of the great auricular nerve coursing into the submandibular region and supplying the platysma muscle, additional to the cervical branches of the facial nerve.

\section{CASE REPORT}

During the dissection of the left side of the neck of an 81-year-old female formaldehyde-embalmed cadaver, an unusual course of the anterior branch of the great auricular nerve was observed to supply the platysma muscle, in addition to the cervical branches of the facial nerve (Fig. 1A). The dissection was performed with the aid of the magnifying lens $(4 \times)$. There were no signs of previous trauma or surgical scars on the face and neck. The parotid fascia and the superficial cervical layer were exposed by dissection of the whole dermal layer from the neck and face.

The great auricular nerve was observed arising from and winding around the posterior border of the sternocleidomastoid muscle, coursing $1 \mathrm{~cm}$ superiorly before dividing into the anterior and posterior branches. Both branches then ascended beneath the platysma muscle on the surface of the sternocleidomastoid muscle. The thicker posterior branch trifurcated at the posterior lobe of the parotid gland by giving two superficial (fascial) and one deep (lobular) branch providing sensory innervation to the skin overlying the parotid gland and inferior part of the auricle.

The anterior branch ascended obliquely over the sternocleidomastoid muscle and turned anteriorly inferior to the apex of the parotid gland, crossing the retromandibular and the internal jugular veins. In the submandibular region the anterior branch of the great auricular nerve entered the deep surface of the platysma muscle. The cervical branch of the facial nerve divided just inferior to the apex of the parotid gland into the thinner anterior and thicker posterior branches, entering separately into the deep surface of the platysma muscle. A short communication connected the thicker cervical branch of the facial nerve and the anterior branch of the great auricular nerve (Fig. 1B).

On the right side, the great auricular nerve coursed over the mid-body of the sternocleidomastoid muscle posterior to the external jugular vein as a single branch and distributed to the skin over the parotid gland.

\section{DISCUSSION}

The present report describes a cadaveric finding of an unusual anatomic variation of the anterior branch 
of the great auricular nerve supplying the platysma muscle additional to the cervical branch of the facial nerve, with communication between both nerves.

The communications between the cervical plexus and the facial nerve are well known and are reported to originate during the seventh week of the embryonic life [5]. Gasser [6] reported that early in embryonic life ( $7^{\text {th }}$ week), the peripheral part of the facial nerve divides into several bundles from which the most caudal bundles communicate with nerves from the second and third cervical ganglia in a plexus located in the caudal and ventral part of the second arch. Another bundle of the facial nerve, the future cervical branch, pursues a ventral course and terminates just deep to the myoblastic lamina from which the platysma muscle develops. The observed anatomical variation could be a consequence of the anterior branch of the great auricular nerve termination deep to the myoblastic lamina rather than in the ventral part of the second arch [6].

Previous reports have already described communications between the great auricular nerve and several cranial nerves. Pillay et al. [9] described a variation in the branching pattern of the great auricular nerve, as well as a communication between the transverse cervical nerve and the great auricular nerve in human foetuses. Yang et al. [11] and Diamond et al. [5] both reported an unusual variation where the posterior branch of the great auricular nerve sends a small nerve twig (or several small twigs) into the parotid parenchyma and connects with the trunk and temporal branch of the facial nerve, the auriculotemporal nerve and the auricular branch of the vagus nerve $[5,10,11]$. Furthermore, Brennan et al. [4] described a communication between the great auricular nerve and the marginal mandibular branch of the facial nerve seen during an elective neck dissection surgery. In this case, by stimulating the anterior branch of the great auricular nerve that communicated with the marginal mandibular nerve, a motor activity in the lower lip was observed.

Although the great auricular nerve is traditionally treated with little interest on the assumption that it is clinically inconsequential, emerging evidence have provided compelling insights into its clinical significance. Toure [10] recently reported that the great auricular nerve is the principal nerve that underlies the gustatory sweating syndrome. Anatomical dissection and histological examination of the great auricular nerve revealed well-formed nerve bundles to small salivary duct and blood vessels that suggested a possible role in the secretory mechanisms of the parotid salivary gland [12]. In addition, it has been proposed that the great auricular nerve might be involved in the coordination of proprioceptive information from the muscle via the motor nerve which it communicates with [11]. Previous reports have consistently shown that the great auricular nerve variants communicate with the facial nerve by terminating in to the nerve trunk $[4,5,10,11]$.

\section{CONCLUSIONS}

Although a distinction has been made in the literature for the great auricular nerve not having a motor component [4], our case report showed that after communicating with the cervical branch of the facial nerve, the anterior branch of the great auricular nerve independently entered the platysma muscle, which suggests a motor function.

\section{Acknowledgements}

We are grateful to Ivan Blažinovič for the dissection work, Stanko Kristl and Friderik Štendler for technical assistance, Nataša Pollak Kristl for the figure labelling, and to Dr. Chiedozie K. Ugwoke for manuscript proofreading. The donor of the body used in the study is respectfully acknowledged. We would also like to thank the Slovenian Research Agency for financial support within the framework of the Programme Group P3-0043.

\section{REFERENCES}

1. Altafulla J, Iwanaga J, Lachkar $S$, et al. The great auricular nerve: anatomical study with application to nerve grafting procedures. World Neurosurg. 2019; 125: e403-e407, doi: 10.1016/j.wneu.2019.01.087, indexed in Pubmed: 30703599.

2. Barbour JR, lorio ML, Halpern DE. Surgical decompression of the great auricular nerve: a therapeutic option for neurapraxia following rhytidectomy. Plast Reconstr Surg. 2014; 133(2):255-260, doi: 10.1097/01.prs.0000436861.85892.a1, indexed in Pubmed: 24150120.

3. Baring DEC, Johnston A, O'Reilly BF. Identification of the accessory nerve by its relationship to the great auricular nerve. J Laryngol Otol. 2007; 121(9): 892-894, doi: 10.1017/ S0022215107006251, indexed in Pubmed: 17295943.

4. Brennan PA, Webb R, Kemidi F, et al. Great auricular communication with the marginal mandibular nerve: a previously unreported anatomical variant. $\mathrm{Br} J$ Oral Maxillofac Surg. 2008; 46(6): 492-493, doi: 10.1016/j. bjoms.2007.12.005, indexed in Pubmed: 18242803.

5. Diamond $\mathrm{M}$, Wartmann $\mathrm{CT}$, Tubbs RS, et al. Peripheral facial nerve communications and their clinical implications. Clin Anat. 2011 ; 24(1): 10-18, doi: 10.1002/ca.21072, indexed in Pubmed: 20941708. 
6. Gasser RF. The development of the facial nerve in man. Ann Otol Rhinol Laryngol. 1967; 76(1): 37-56, doi: 10.1177/000348946707600103, indexed in Pubmed: 6020340.

7. George M, Karkos PD, Dwivedi RC, et al. Preservation of greater auricular nerve during parotidectomy: sensation, quality of life, and morbidity issues. A systematic review. Head Neck. 2014; 36(4): 603-608, doi: 10.1002/ hed.23292, indexed in Pubmed: 23766239.

8. Lefkowitz T, Hazani R, Chowdhry S, et al. Anatomical landmarks to avoid injury to the great auricular nerve during rhytidectomy. Aesthet Surg J. 2013; 33(1): 19-23, doi: 10.1177/1090820X12469625, indexed in Pubmed: 23277616.

9. Pillay $P$, Partab $P$, Lazarus $L$, et al. The great auricular nerve in fetuses. Int J Morphol. 2012; 30(1): 40-44, doi: 10.4067/ s0717-95022012000100006.
10. Toure G. Intraparotid location of the great auricular nerve: a new anatomical basis for gustatory sweating syndrome. Plast Reconstr Surg. 2015; 136(5): 1069-1081, doi: 10.1097/PRS.0000000000001726, indexed in Pubmed: 26505708.

11. Yang HM, Kim HJ, Hu KS. Anatomic and histological study of great auricular nerve and its clinical implication. J Plast Reconstr Aesthet Surg. 2015; 68(2): 230-236, doi: 10.1016/j.bjps.2014.10.030, indexed in Pubmed: 25465135.

12. Zohar Y, Siegal A, Siegal G, et al. The great auricular nerve; does it penetrate the parotid gland? An anatomical and microscopical study. J Craniomaxillofac Surg. 2002; 30(5): 318-321, doi: 10.1016/s1010-5182(02)90287-8, indexed in Pubmed: 12377206. 